Research Paper

\title{
Significant Prognostic Impact of Chemoradiotherapy- Induced Hemoglobin Decrease on Treatment Outcomes of Nasopharyngeal Carcinoma
}

\author{
Xue-Xia Liang1,3†, Qun Li1, $2 \dagger$, Zhen Su1,2†, Xiao-Wen Lan¹, 2, Pu-Yun Ouyang1, 2, Yan-Ping Mao1, 2, Ding-Bo \\ Shi $^{1}$, Wu-Guo Deng ${ }^{1}$, Zhi-Bin Cheng ${ }^{3}$, Si-Yang Wang ${ }^{3}$, Fang-Yun Xie ${ }^{1,2}$ \\ 1. State Key Laboratory of Oncology in South China, Collaborative Innovation Center of Cancer Medicine, Sun Yat-sen University Cancer Center, \\ 651 Dongfeng East Road, Guangzhou 510060, China. \\ 2. Department of Radiation Oncology, Sun Yat-sen University Cancer Center, 651 Dongfeng East Road, Guangzhou 510060, China. \\ 3. Department of Radiation Oncology, the Fifth Affiliated Hospital of Sun Yat-sen University, 52 Meihua East Road, Zhuhai 519000, China. \\ † These authors contributed equally to this article.
}

$\triangle$ Corresponding author: Fang-yun Xie, Sun Yat-sen University Cancer Center, 651 Dongfeng East Road, Guangzhou 510060, China. Tel: +86-2087343484. E-mail: xiefy@sysucc.org.cn

(c) 2015 Ivyspring International Publisher. Reproduction is permitted for personal, noncommercial use, provided that the article is in whole, unmodified, and properly cited. See http://ivyspring.com/terms for terms and conditions.

Received: 2014.12.20; Accepted: 2015.02.10; Published: 2015.04.02

\begin{abstract}
Purpose: To investigate prognostic impact of chemoradiotherapy-induced hemoglobin $(\mathrm{Hb})$ decrease on treatment outcomes of endemic nasopharyngeal carcinoma (NPC).

Materials and Methods: Eight hundred and fifteen non-metastatic NPC, receiving neoadjuvant chemotherapy followed by radiotherapy (NACT+RT group) or concomitant chemoradiotherapy (CCRT group), were enrolled in this study, who were regrouped according to pre-radiotherapy $\mathrm{Hb}$ (pre- $\mathrm{RT} \mathrm{Hb}$ ), post-radiotherapy $\mathrm{Hb}$ (post- $\mathrm{RT} \mathrm{Hb}$ ) and individual $\mathrm{Hb}$ decrease through radiotherapy or CCRT $(\triangle \mathrm{Hb})$, respectively. Survival curves were estimated using Kaplan-Meier method and compared by log-rank test. Multivariate analysis was performed using the COX proportional hazard model and binary logistic regression model.
\end{abstract}

Results: A poorer 5-year disease-free survival (DFS) was observed when pre-RT $\mathrm{Hb}<130.00 \mathrm{~g} / \mathrm{L}$. However, post-RT $H \mathrm{~b}<130.00 \mathrm{~g} / \mathrm{L}$ was associated with significantly poorer 5 -year locoregional recurrence-free survival $(\mathrm{LRFS})(P=0.010)$ and disease specific survival $(\mathrm{DSS})(P=0.008)$. Multivariate analysis with the COX proportional hazard model identified post-RT $\mathrm{Hb}<130.00 \mathrm{~g} / \mathrm{L}$ as an independent negative prognostic factor for both LRFS (hazard ratio [HR], 1.896; 95\% confidence interval $[\mathrm{Cl}], 1.158-3.106 ; P=0.011)$ and DSS (HR, 1.767; 95\% Cl, 1.152-2.711; $P=0.009)$. Similarly, $\Delta \mathrm{Hb}<-15.00 \mathrm{~g} / \mathrm{L}$ also predicted poorer 5 -year LRFS $(P=0.024)$ and DSS $(P=0.015)$, which was confirmed in multivariate analysis as an independent adverse prognostic factor for LRFS (HR, 1.586; $95 \% \mathrm{Cl}, 1.058-2.377 ; P=0.026)$ and DSS (HR, 1.556; 95\% Cl, 1.087-2.227; $P=0.016)$, respectively. Multivariate analysis with binary logistic regression model indicated that CCRT was a significantly independent predictor for post-RT $\mathrm{Hb}<130.00 \mathrm{~g} / \mathrm{L}$ and $\Delta \mathrm{Hb}<-15.00 \mathrm{~g} / \mathrm{L}$.

Conclusions: Chemoradiotherapy-induced decreased $\mathrm{Hb}$ levels have negative influence on locoregional control and survival, and might counteract the benefit of neoadjuvant/concomitant chemotherapy. Further studies on supportive care to maintain sufficient $\mathrm{Hb}$ level during chemo-radiotherapy are warranted.

Key words: concomitant chemotherapy, hemoglobin decrease, nasopharyngeal carcinoma, neoadjuvant chemotherapy, prognostication, radiotherapy. 


\section{Introduction}

Hypoxia induced radio-resistance has been acknowledged for decades [1-2]. Evidences for detrimental effect of tumor hypoxia on radiotherapy are obtained indirectly from the associations between tumor local control or survival and $\mathrm{Hb}$ levels [3-13]. $\mathrm{Hb}$ is an oxygen-carrying molecule which brings oxygen to terminal ends of microvessels, where tissue oxygen concentration is low, and exchanges oxygen with carbon dioxide $\left(\mathrm{CO}_{2}\right)$. Decreased $\mathrm{Hb}$ level worsens tumor oxygen deficiency, increases hypoxic cells and contributes to the development of radio-resistance and poor prognosis [14-15]. Low $\mathrm{Hb}$ level has been reported to be an adverse prognostic factor in radiotherapeutic management of various tumors (e.g., squamous cell cancer of head and neck (HNSCC) [3, 5 11, 13], cervical cancer [4, 12], non-small cell lung cancer [6], anal cancer [7], glioma [8], bladder cancer [9], esophageal cancer [10, 16], et al). In general, high $\mathrm{Hb}$ level was reported to be associated with better probability of tumor local control and survival, while decreased $\mathrm{Hb}$ level correlated with poorer prognosis [3-5, 7-11, 13, 16]. However, what these individual studies were not consistent with was that whether pre-RT $\mathrm{Hb}$ or mid-RT $\mathrm{Hb}$ or post-RT $\mathrm{Hb}$ or $\Delta \mathrm{Hb}$ actually affected treatment outcomes of chemoradiotherapy and the optimum cut-off point of $\mathrm{Hb}$ for prognostication [3-13, 16].

Nasopharyngeal carcinoma (NPC) is a unique type of cancer among head and neck malignancy, in terms of its highest prevalence in Guangdong Province of southern China, poor pathological differentiation, with most classified as undifferentiated non-keratinized carcinoma in endemic area, proven association with Epstein-Barr virus infection, strong propensity to metastasize to regional lymphatic and/or distant organs, and chemo-radiosensitivity [17]. Radiotherapy is the preferred management for NPC due to its sensitivity to irradiation and anatomical adjacency or invasion to critical cranial base structures which limits locoregional surgery. For locoregional advanced NPC (LA-NPC), chemo-radiotherapy is recommended as standard treatment [17]. However, locoregional relapse and distant metastasis are still the main failure patterns for LA-NPC even treated by combined therapy [17]. In chemoradiotherapy setting, marrow suppression, causing mild-to-moderate anemia, is more prevalent than in RT alone and results in decreased $\mathrm{Hb}$ level [18]. However, literatures on prognostic impact of $\mathrm{Hb}$ decrease for NPC in chemoradiotherapy setting are still rare. Herein, we report this study about the influence of pre-RT $\mathrm{Hb}$, post-RT $\mathrm{Hb}$, and $\Delta \mathrm{Hb}$ on treatment outcomes for NPC receiving neoadjuvant chemotherapy followed by definitive radiotherapy
(NACT+RT group) or concomitant chemoradiotherapy (CCRT group) both using cisplatin-based regimens.

\section{Materials and Methods}

\section{Patient Enrollment and Pre-treatment Evalu- ation}

This study was approved by the Clinical Ethics Review Board of Sun Yat-sen University Cancer Center. Between January 2004 and December 2007, patients with newly diagnosed, nonmetastatic and histologically proven NPC, receiving NACT+RT or CCRT and having $\mathrm{Hb}$ tested before, during and after radiotherapy/CCRT in Sun Yat-sen University Cancer Center, were enrolled in this analysis. Routine pre-treatment evaluation included history, physical examination, optic fiber nasopharyngoscopy, magnetic resonance imaging (MRI) or computerized tomography (CT) of nasopharynx and neck, chest radiograph, abdominal ultrasonography, bone scanning, a complete blood count and a biochemical profile. Enhanced CT scanning or positron emission tomography/computerized tomography (PET/CT), even biopsy when necessary, was done for the workup of potential distant metastasis. Restaging was done by revising pre-treatment evaluation according to the American Joint Committee on Cancer (AJCC) staging system 2010 clinical classification (the seventh edition).

\section{Treatment}

According to treatment practice for LA-NPC during the study period in our center, neoadjuvant chemotherapy (NACT), administered for three cycles with an interval of three weeks, was as follow: cisplatin $\left(80 \mathrm{mg} / \mathrm{m}^{2}\right.$ by intravenous drip [iv drip] on $\left.\mathrm{d}_{1}\right)$ and 5-fluorouracil (5-FU) $\left(3.75 \mathrm{~g} / \mathrm{m}^{2}\right.$ by continuous intravenous infusion [civ] for 120 hours) [19]. Two hundred and seventy-five $(75.1 \%)$ patients received three cycles of full-dose NACT, and $54(14.8 \%)$ patients received three cycles of NACT with at least one cycle dose reduced by $20 \%$. Thirty-seven $(10.1 \%)$ patients quit the third cycle. The mean dose intensities were $23.3 \mathrm{mg} / \mathrm{m}^{2} /$ week for cisplatin and $1.03 \mathrm{~g} / \mathrm{m}^{2} /$ week for 5-FU.

Concomitant chemotherapy was as follow: (1) cisplatin at a dose of $80 \mathrm{mg} / \mathrm{m}^{2}$ by iv drip on weeks 1 , 4 and/or 7 [20]; or (2) weekly cisplatin at a dose of 40 $\mathrm{mg} / \mathrm{m}^{2}$ by iv drip [21]. Weekly cisplatin was administered to 185 patients while 264 patients received cisplatin administered at an interval of three weeks. In the every three weeks group, 231 patients received two cycles without delay, and 12 patients received two cycles with more than a week delayed and 21 
patients received three cycles. In the weekly group, 159 patients received more than five cycles and 12 patients received seven cycles. The mean dose intensities were $24.8 \mathrm{mg} / \mathrm{m}^{2} /$ week and $29.1 \mathrm{mg} / \mathrm{m}^{2} /$ week for the every three weeks group and the weekly group, respectively.

Definitive radiotherapy was performed utilizing high energy $6 \mathrm{MV}$ X-ray produced by linear accelerators. Six hundred and fifty-eight $(80.7 \%)$ patients received conventionally fractionated two-dimensional conformal radiotherapy (2D-CRT) with a dose of 2.0 Gy per fraction and total dose of 66-74 Gy. One hundred and forty-two (17.4\%) patients and $15(1.8 \%)$ patients were treated by intensity-modulated radiotherapy (IMRT) and three-dimensional conformal radiotherapy (3D-CRT), respectively. Every patient was irradiated once a day from Monday to Friday every week. For NACT+RT group, radiotherapy was initiated three weeks after the last cycle of NACT. Details on implementing IMRT/3D-CRT and 2D-CRT in Sun Yat-sen University Cancer Center were reported previously [20, 22].

\section{Hb Measurement and Definition}

$\mathrm{Hb}$ level and a complete blood count were measured before RT/CCRT, during RT/CCRT once a week, and at the last week before completing RT/CCRT. Blood sample was collected from veins of either upper limb under fasting status in the morning and tested within one hour. Reference scales of $\mathrm{Hb}$ levels were $140 \sim 180 \mathrm{~g} / \mathrm{L}$ and 120 160 g/L for male and female, respectively. Pre-RT $\mathrm{Hb}$ denoted $\mathrm{Hb}$ level tested before RT/CCRT. Post-RT Hb denoted $\mathrm{Hb}$ level tested at the last week of RT/CCRT, and $\Delta \mathrm{Hb}$ was defined as the $\mathrm{Hb}$ level equal to post- $\mathrm{RT} \mathrm{Hb}$ minus pre-RT Hb.

\section{Follow-up and Survivals Assessment}

After completing chemoradiotherapy, patients were observed every three months during the first three years, and every six months during the fourth to fifth year, and once a year thereafter. Disease-specific survival (DSS), the primary endpoint in this study, was defined as the time from finishing radiotherapy to the date of death from cancer or when censored at the latest date if patients were still alive. Disease-free survival (DFS) was defined as the time from finishing radiotherapy to the date of the first-discovered tumor recurrence at any site or the latest date of a follow-up when censored. Locoregional recurrence-free survival (LRFS) and distant metastases-free survival (DMFS) were defined as the time from completing radiotherapy to the date of the first-discovered locoregional recurrence in irradiation fields and the first-discovered distant metastasis or the latest date of a follow-up when censored, respectively.

\section{Statistical Analysis}

SPSS software (version 13.0, SPSS, Chicago, IL, USA) was used to perform statistical analysis and two-tailed $P$ values $<0.05$ were considered statistically significant. Pearson chi-square test of independence, as a univariate analysis, was used to analyze the associations between clinicopathological characteristics and $\mathrm{Hb}$ levels. $\mathrm{Hb}$ levels comparisons were performed using one-way ANOVA (analysis of variance) with $L S D$ - $t$ test. Life table method was employed to calculate cumulative survival rates. Univariate analysis for survivals was done using Kaplan-Meier method and log-rank test, by which differences of estimated survival curves were also determined. Multivariate analysis was performed using the COX proportional hazards model to determine independent prognostic factors and to calculate hazard ratio (HR) and 95\% confidence index (CI) as well. Receiver operating characteristic (ROC) curve analysis was used to evaluate different cut-off points for Hb levels and identify an optimum cut-off point, according to which all patients, NACT+RT group, and CCRT group were further regrouped. Multivariate analysis using the binary logistic regression model was performed to identify the most relevant clinicopathological characteristics associated with decreased pre-RT $\mathrm{Hb}$, post-RT $\mathrm{Hb}$ and $\Delta \mathrm{Hb}$, respectively.

\section{Results}

\section{Patient characteristics}

There were 815 patients eligible for evaluation, whose characteristics were summarized in Table 1, where the univariate analysis of associations between clinicopathological characteristics and $\mathrm{Hb}$ levels was also shown. The entire cohort had 616 (75.6\%) men and 199 (24.4\%) women, with a male-to-female ratio of 3.09:1. Pathologically, $96.7 \%$ (788/815) of the patients was diagnosed as undifferentiated or differentiated non-keratinized carcinoma, and two patients had adenocarcinoma. Median age of the entire cohort was 44.0 years (range, 13-80 years). Median follow-up was 60.7 months (range, 5.3-77.8 months).

\section{Pre-RT Hb, post-RT Hb, $\Delta \mathrm{Hb}$ and cut-off points of $\mathrm{Hb}$ levels}

The averages and medians of pre- $\mathrm{RT} \mathrm{Hb}$ were $136.98 \mathrm{~g} / \mathrm{L}$ (standard deviation, SD: $\pm 16.68 \mathrm{~g} / \mathrm{L}$ ) and $138.00 \mathrm{~g} / \mathrm{L}$ (range, $88.00 \sim 183.00 \mathrm{~g} / \mathrm{L}$ ), $130.88 \mathrm{~g} / \mathrm{L}$ (SD: $\pm 15.62 \mathrm{~g} / \mathrm{L}$ ) and $131.00 \mathrm{~g} / \mathrm{L}$ (range, $90.00 \mathrm{~g} / \mathrm{L} \sim 177.50$ $\mathrm{g} / \mathrm{L}), 143.39 \mathrm{~g} / \mathrm{L}(\mathrm{SD}: \pm 15.31 \mathrm{~g} / \mathrm{L})$ and $145.00 \mathrm{~g} / \mathrm{L}$ (range, $88.00 \mathrm{~g} / \mathrm{L} \sim 183.00 \mathrm{~g} / \mathrm{L}$ ) for all patients, NACT+RT group and CCRT group, respectively. The averages and medians of post-RT Hb were $121.99 \mathrm{~g} / \mathrm{L}$ 
(SD: $\pm 16.32 \mathrm{~g} / \mathrm{L}$ ) and $121.00 \mathrm{~g} / \mathrm{L}$ (range, 78.00 171.00g/L), $128.36 \mathrm{~g} / \mathrm{L}(\mathrm{SD}: \pm 15.97 \mathrm{~g} / \mathrm{L}$ ) and $128.00 \mathrm{~g} / \mathrm{L}$ (range, $79.00 \mathrm{~g} / \mathrm{L} \sim 171.00 \mathrm{~g} / \mathrm{L}$ ), $116.90 \mathrm{~g} / \mathrm{L}$ (SD: $\pm 14.75 \mathrm{~g} / \mathrm{L}$ ) and $116.00 \mathrm{~g} / \mathrm{L}$ (range, 78.00 $\mathrm{g} / \mathrm{L} 166.00 \mathrm{~g} / \mathrm{L}$ ) for the 815 patients, NACT+RT group and CCRT group, respectively. The averages and medians of $\Delta \mathrm{Hb}$ level were $-15.00 \mathrm{~g} / \mathrm{L}$ (SD: \pm 14.93 $\mathrm{g} / \mathrm{L}$ ) and $-14.00 \mathrm{~g} / \mathrm{L}$ (range, $-59.90 \sim 36.00 \mathrm{~g} / \mathrm{L}$ ), -9.03 g/L (SD: $\pm 12.97 \mathrm{~g} / \mathrm{L}$ ) and $-9.00 \mathrm{~g} / \mathrm{L}$ (range, -59.00 $\mathrm{g} / \mathrm{L} 36.00 \mathrm{~g} / \mathrm{L}),-19.78 \mathrm{~g} / \mathrm{L}(\mathrm{SD}: \pm 14.68 \mathrm{~g} / \mathrm{L}$ ) and $-19.00 \mathrm{~g} / \mathrm{L}$ (range, $-59.00 \mathrm{~g} / \mathrm{L} \sim 25.00 \mathrm{~g} / \mathrm{L}$ ) for all patients, NACT+RT group and CCRT group, respectively. Figure 1A, Figure $1 \mathrm{~B}$ and Figure $1 \mathrm{C}$ showed comparisons of pre-RT $\mathrm{Hb}$, post-RT $\mathrm{Hb}$ and $\Delta \mathrm{Hb}$ and indicated their pairwise significant difference in all patients, CCRT group, and NACT+RT group, respectively.

According to the National Cancer Institute (NCI) toxicity criteria (CTCAE v3.0), before RT/CCRT, $57.9 \%$ (472/815), 39.1\% (319/815), 2.9\% (24/815) and $0 \%$ of all patients had no anemia, mild anemia (grade 1 ), moderate anemia (grade 2) and severe anemia (more than grade 3), respectively; while after RT/CCRT, the corresponding data were $22.0 \%$ (179/815), 67.9\% (553/815), 7.2\% (59/815) and 2.9\% (24/815), respectively (Figure 1D). The pre-RT anemia degrees were comparable between CCRT group and NACT+RT group (Figure 1E). However, more patients in CCRT group suffered mild-to-moderate post-RT anemia than in NACT+RT group (Figure 1F).

For DSS, areas under the ROC curves (AUCs) of $\triangle \mathrm{Hb}$, post- $\mathrm{RT} \mathrm{Hb}$ and pre- $\mathrm{RT} \mathrm{Hb}$ were $0.573(95 \% \mathrm{CI}$ : $0.518 \sim 0.628, P=0.011), 0.591$ (95\% CI: 0.534 0.647, $P=0.002$ ) and 0.533 (95\% CI: 0.476 0.591, $P=0.246$ ), respectively (Supplementary Figure S1A). The cut-off points of post- $\mathrm{RT} \mathrm{Hb}$ and $\Delta \mathrm{Hb}$ were $130.00 \mathrm{~g} / \mathrm{L}$ (the sensitivity was 0.754 and the specificity was 0.387 ) and $-15.00 \mathrm{~g} / \mathrm{L}$ (the sensitivity was 0.568 and the specificity was 0.604), respectively. However, the cut-off point for pre-RT $\mathrm{Hb}$ was $130.00 \mathrm{~g} / \mathrm{L}$ based on literatures $[7,10,23]$, since no statistical significance was observed in the ROC analysis of pre-RT $\mathrm{Hb}$ for DSS.

Table 1 Clinicopathological characteristics of 815 nasopharyngeal carcinoma patients and their associations with pre-RT Hb, post-RT Hb and $\Delta \mathrm{Hb}$ levels, respectively.

\begin{tabular}{|c|c|c|c|c|c|c|c|c|c|}
\hline \multirow[t]{2}{*}{ Characteristics } & \multicolumn{3}{|c|}{ Pre-RT Hb level } & \multicolumn{3}{|c|}{ Post-RT Hb level } & \multicolumn{3}{|c|}{$\Delta \mathrm{Hb}$ level } \\
\hline & $\begin{array}{l}<130.00 \mathrm{~g} / \mathrm{L} \\
\mathrm{n}(\%)\end{array}$ & $\begin{array}{l}\geq 130.00 \mathrm{~g} / \mathrm{L} \\
\mathrm{n}(\%)\end{array}$ & $P$ value ${ }^{a}$ & $\begin{array}{l}<130.00 \mathrm{~g} / \mathrm{L} \\
\mathrm{n}(\%)\end{array}$ & $\begin{array}{l}\geq 130.00 \mathrm{~g} / \mathrm{L} \\
\mathrm{n}(\%)\end{array}$ & $P$ valuea & $\begin{array}{l}\geq-15.00 \mathrm{~g} / \mathrm{L} \\
\mathrm{n}(\%)\end{array}$ & $\begin{array}{l}<-15.00 \mathrm{~g} / \mathrm{L} \\
\mathrm{n}(\%)\end{array}$ & $P$ valuea \\
\hline Gender & & & $<0.001$ & & & $<0.001$ & & & 0.013 \\
\hline Male & 150(18.4) & $466(57.2)$ & & $373(45.8)$ & $243(29.8)$ & & $327(40.1)$ & $289(35.5)$ & \\
\hline Female & $112(13.7)$ & $86(10.6)$ & & $172(21.1)$ & $26(3.2)$ & & $125(15.3)$ & $73(9.0)$ & \\
\hline Age (years) & & & 0.233 & & & 0.071 & & & 0.650 \\
\hline$<44$ & $120(14.7)$ & $278(34.1)$ & & $254(31.2)$ & 144(17.7) & & $218(26.7)$ & 180(22.1) & \\
\hline$\geq 44$ & 142(17.4) & $275(33.7)$ & & $291(35.7)$ & $126(15.5)$ & & $235(28.8)$ & $182(22.3)$ & \\
\hline Pathology & & & 0.813 & & & 0.078 & & & 0.671 \\
\hline K & $7(0.9)$ & $13(1.6)$ & & $11(1.3)$ & $9(1.1)$ & & $10(1.2)$ & $10(1.2)$ & \\
\hline $\mathrm{D}$ & $15(1.8)$ & $39(4.8)$ & & $31(3.8)$ & $23(2.8)$ & & $29(3.5)$ & $25(3.1)$ & \\
\hline $\mathrm{U}$ & $240(29.4)$ & $494(60.6)$ & & $503(61.7)$ & $231(28.3)$ & & $408(50.1)$ & $326(40.0)$ & \\
\hline A & $0(0)$ & $2(0.2)$ & & $0(0)$ & $2(0.2)$ & & $1(0.1)$ & $1(0.1)$ & \\
\hline T stage ${ }^{b}$ & & & 0.004 & & & $<0.001$ & & & 0.770 \\
\hline $\mathrm{T}_{1}$ & $24(2.9)$ & $63(7.7)$ & & $42(5.1)$ & $45(5.5)$ & & $52(6.4)$ & $35(4.3)$ & \\
\hline $\mathrm{T}_{2}$ & $59(7.2)$ & $168(20.6)$ & & 142(17.4) & $85(10.4)$ & & $127(15.6)$ & $100(12.2)$ & \\
\hline $\mathrm{T}_{3}$ & $96(11.8)$ & $203(24.9)$ & & $205(25.1)$ & $94(11.5)$ & & 160(19.6) & 139(17.0) & \\
\hline $\mathrm{T}_{4}$ & 82(10.1) & 114(14.0) & & $155(19.0)$ & $41(5.0)$ & & $108(13.2)$ & $88(10.8)$ & \\
\hline N stage st & & & $<0.001$ & & & $<0.001$ & & & 0.030 \\
\hline $\mathrm{N}_{0}$ & $26(3.2)$ & 90(11.0) & & $53(6.5)$ & $63(7.7)$ & & $75(9.2)$ & $41(5.0)$ & \\
\hline $\mathrm{N}_{1}$ & $126(15.5)$ & $309(37.9)$ & & $289(35.4)$ & $146(17.9)$ & & $230(28.2)$ & $205(25.1)$ & \\
\hline $\mathrm{N}_{2}$ & $95(11.6)$ & $132(16.2)$ & & $173(21.2)$ & $54(6.6)$ & & $130(15.9)$ & $97(11.9)$ & \\
\hline $\mathrm{N}_{3 a-b}$ & $14(1.7)$ & $17(2.1)$ & & $29(3.5)$ & $2(0.2)$ & & $12(1.5)$ & $19(2.3)$ & \\
\hline $\mathrm{NACT}+\mathrm{RT}$ & & & $<0.001$ & & & $<0.001$ & & & 0.010 \\
\hline Yes & $165(22.9)$ & $201(28.0)$ & & 286(39.7) & $80(11.1)$ & & $220(30.5)$ & $146(20.3)$ & \\
\hline No & $84(9.2)$ & $365(39.9)$ & & $248(27.1)$ & $201(22.0)$ & & $229(25.0)$ & $220(24.0)$ & \\
\hline CCRT & & & 0.921 & & & $<0.001$ & & & $<0.001$ \\
\hline Yes & $145(17.8)$ & 304(37.3) & & $352(43.2)$ & $97(11.9)$ & & 188(23.1) & $261(32.0)$ & \\
\hline No & 117(14.3) & 249(30.5) & & $193(23.7)$ & $173(21.2)$ & & $265(32.5)$ & $101(12.4)$ & \\
\hline
\end{tabular}

a Pearson chi-square test of independence; ${ }^{b}$ according to the American Joint Committee on Cancer (AJCC) staging system 2010 clinical classification (the seventh edition). Abbreviations: K, keratinized carcinoma; D, differentiated non-keratinized carcinoma; U, undifferentiated non-keratinized carcinoma; A, adenocarcinoma; NACT+RT, neoadjuvant chemotherapy followed by radiotherapy alone; CCRT, concurrent chemoradiotherapy; RT, radiotherapy; Hb, hemoglobin. 

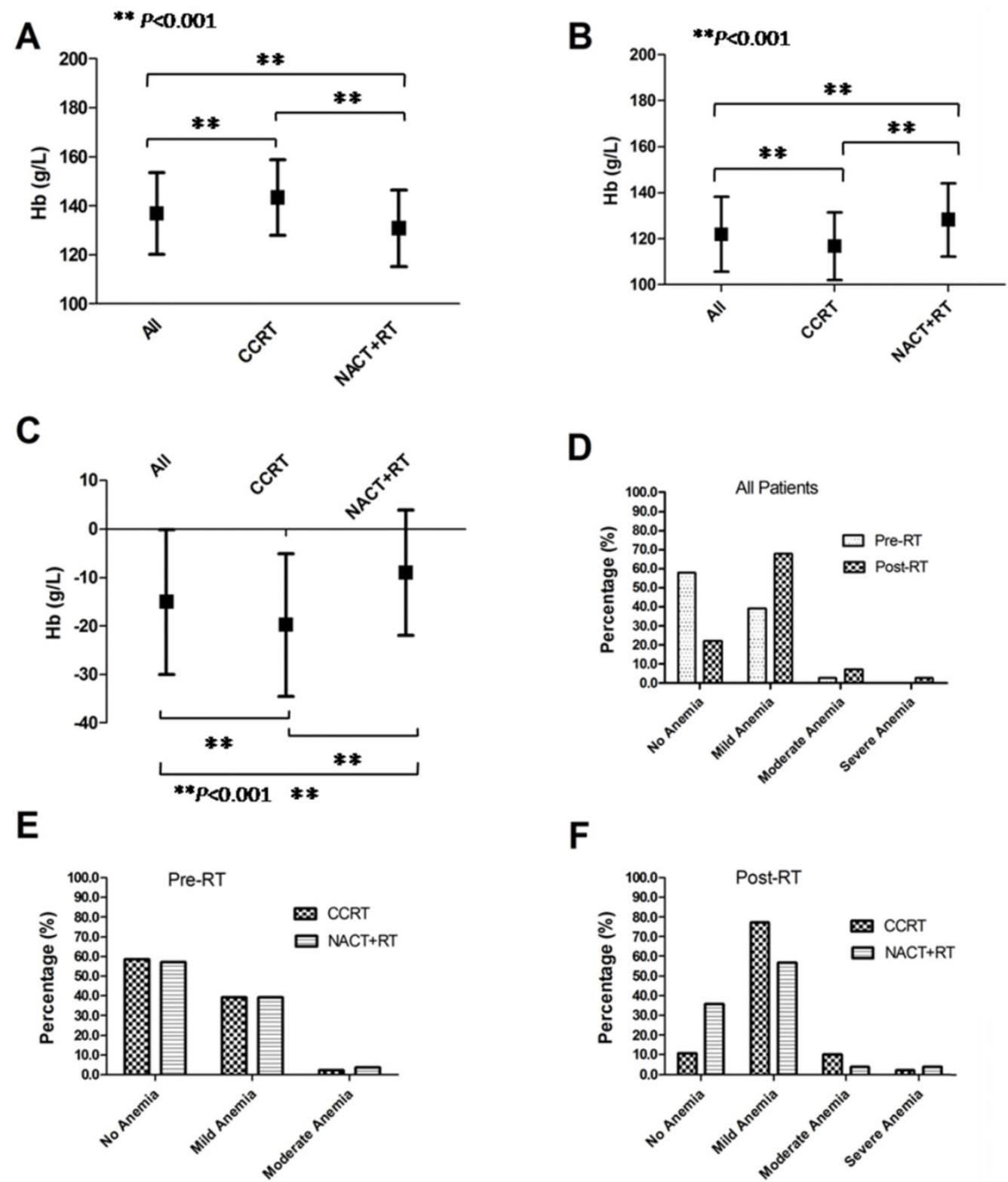

Figure 1 Pre-RT Hb level (A), post-RT Hb level (B) and $\triangle \mathrm{Hb}$ level $(C)$ of all patients, CCRT group and NACT+RT group, respectively; pre-RT and post-RT anemia distribution (D) in all patients; Pre-RT anemia $(E)$ and post-RT anemia (F) distribution in CCRT group and NACT+RT group, respectively. Abbreviation: RT, radiotherapy; Hb, hemoglobin; CCRT, concurrent chemoradiotherapy; NACT+RT, neoadjuvant chemotherapy followed by radiotherapy.

\section{Associations between $\mathrm{Hb}$ levels and survivals}

In univariate analysis, pre- $\mathrm{RT} \mathrm{Hb}<130.00 \mathrm{~g} / \mathrm{L}$ showed a deleterious impact on 5-year DFS comparing to that of $\geq 130.00 \mathrm{~g} / \mathrm{L}$ ( $76 \%$ vs. $82 \%, P=0.033$, figure 2A). There was no apparent association between pre-RT $\mathrm{Hb}$ and LRFS, DMFS, or DSS. Within CCRT group, no association between pre- $\mathrm{RT} \mathrm{Hb}$ and DFS was indicated, and 5-year DFS for patients with pre- $\mathrm{RT} \mathrm{Hb} \geq 130.00 \mathrm{~g} / \mathrm{L}$ and $<130.00 \mathrm{~g} / \mathrm{L}$ were $81 \%$ and $77 \%$, respectively $(P=0.157)$. The corresponding data for patients in NACT+RT group were $83 \%$ and $74 \%$, respectively $(P=0.103)$.

Patients with post-RT $\mathrm{Hb}<130.00 \mathrm{~g} / \mathrm{L}$ had poorer LRFS ( $84 \%$ vs. $91 \%, P=0.010$; figure $2 \mathrm{~B}$ ) and
DSS ( $80 \%$ vs. $85 \%, P=0.008$; figure $2 \mathrm{C}$ ) than those with post-RT $\mathrm{Hb} \geq 130.00 \mathrm{~g} / \mathrm{L}$. However, post-RT $\mathrm{Hb}$ did not significantly affect DMFS or DFS. An association between post-RT $\mathrm{Hb}$ and LRFS was detected in CCRT group (Supplementary Figure S1B) but not in NACT+RT group. Five-year LRFS for patients with post-RT $\mathrm{Hb} \geq 130.00 \mathrm{~g} / \mathrm{L}$ and $<130.00 \mathrm{~g} / \mathrm{L}$ in CCRT group were $91 \%$ and $84 \%$, respectively $(P=0.032)$. And corresponding data for those in NACT + RT group were $91 \%$ and $85 \%$, respectively $(P=0.195)$. However, post-RT $\mathrm{Hb}$ affected 5-year DSS in NACT+RT group (Supplementary Figure S1C) but not in CCRT group. In NACT+RT group, 5-year DSS for patients with post-RT $\mathrm{Hb} \geq 130.00 \mathrm{~g} / \mathrm{L}$ and $<130.00 \mathrm{~g} / \mathrm{L}$ were $86 \%$ and $78 \%$, respectively $(P=0.013)$. Corresponding data 
for those in CCRT group were $84 \%$ and $81 \%$, respectively $(P=0.225)$.

$\Delta \mathrm{Hb}<-15.00 \mathrm{~g} / \mathrm{L}$ was also significantly related to inferior LRFS (83\% vs.89\%, $P=0.024$; figure $2 \mathrm{D})$ and DSS (78\% vs. $85 \%, P=0.015$; figure $2 \mathrm{E}$ ). However, $\Delta \mathrm{Hb}$ was not significantly associated with DMFS or DFS. In CCRT group, 5-year LRFS for patients with $\Delta \mathrm{Hb}$ $<-15.00 \mathrm{~g} / \mathrm{L}$ was $82 \%$, compared with $90 \%$ for those with $\Delta \mathrm{Hb} \geq-15.00 \mathrm{~g} / \mathrm{L}(P=0.074$, Supplementary Figure S1D). Corresponding data for patients in $\mathrm{NACT}+\mathrm{RT}$ group were $86 \%$ and $88 \%$, respectively $(P=0.320)$. Five-year DSS for patients in CCRT group with $\Delta \mathrm{Hb}<-15.00 \mathrm{~g} / \mathrm{L}$ and $\geq-15.00 \mathrm{~g} / \mathrm{L}$ were $79 \%$ and $85 \%$, respectively $(P=0.095$, Supplementary Figure $\mathrm{S} 1 \mathrm{E})$. For patients in NACT $+\mathrm{RT}$ group, corresponding data were $74 \%$ and $85 \%$, respectively ( $P=0.078$, Supplementary Figure S1F).

Besides, age ( $\geq 44$ years vs. $<44$ years), gender (female vs. male), $\mathrm{T}$ stage, $\mathrm{N}$ stage, treatment (CCRT vs. NACT+RT), and RT technique (IMRT/3D-CRT vs. 2D-CRT) were tested to investigate their influence on treatment outcomes (Table 2). Age $<44$ years, female, CCRT, early $\mathrm{T}$ stage and $\mathrm{N}$ stage were favorable to
DSS. Female, CCRT, early T stage and $\mathrm{N}$ stage were associated with improved DFS and DMFS. Early N stage predicted higher LRFS while IMRT/3D-CRT showed a borderline favorable effect on LRFS.

In multivariate analysis with the COX proportional hazard regression model, early $\mathrm{N}$ stage, post-RT $\mathrm{Hb} \geq 130.00 \mathrm{~g} / \mathrm{L}$ and $\Delta \mathrm{Hb} \geq-15.00 \mathrm{~g} / \mathrm{L}$ were significantly independent favorable prognostic factors for LRFS. Age $<44$ years, female, early T stage, early N stage, post-RT $\mathrm{Hb} \geq 130.00 \mathrm{~g} / \mathrm{L}$ and $\Delta \mathrm{Hb} \geq-15.00 \mathrm{~g} / \mathrm{L}$ were independent predictors for favorable DSS (Table $3)$.

\section{Multivariate Analysis with Binary Logistic Re- gression Model}

The results of binary logistic regression analysis were shown in Supplementary Table S1. Female, $\mathrm{T}_{4}$ stage and $\mathrm{N}_{2 \sim 3 a-b}$ stage were the most relevant factors for pre-RT $\mathrm{Hb}<130.00 \mathrm{~g} / \mathrm{L}$. Female, age $\geq 44$ years, $\mathrm{T}_{3 \sim 4}$ stage, $\mathrm{N}_{1 \sim 3 a-b}$ stage, and receiving CCRT were predictive of post-RT $\mathrm{Hb}<130.00 \mathrm{~g} / \mathrm{L}$. Male and receiving CCRT were the most relevant parameters for $\Delta \mathrm{Hb}$ $<-15.00 \mathrm{~g} / \mathrm{L}$.
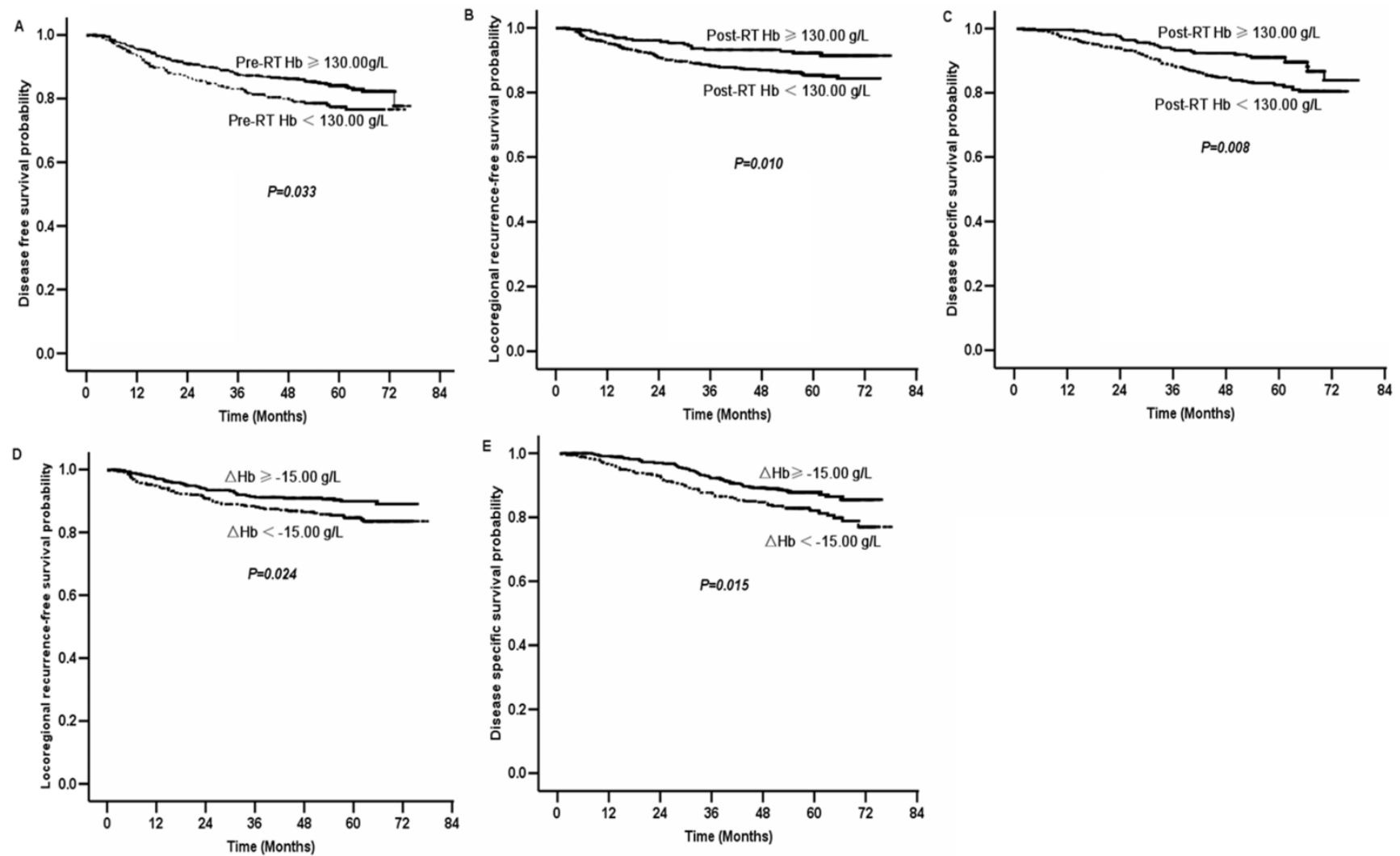

Figure 2 Survival curves of nasopharyngeal carcinoma patients grouped by $\mathrm{Hb}$ levels. Disease-free survival curves of all patients with pre-RT $\mathrm{Hb} \geq 130.00$ $\mathrm{g} / \mathrm{L}$ and pre- $\mathrm{RT} \mathrm{Hb}<130.00 \mathrm{~g} / \mathrm{L}(\mathrm{A})$; locoregional recurrence-free survival curves $(\mathrm{B})$ and disease specific survival curves $(\mathrm{C})$ of all patients with post-RT $\mathrm{Hb}$ $\geq 130.00 \mathrm{~g} / \mathrm{L}$ and post- $\mathrm{RT} \mathrm{Hb}<130.00 \mathrm{~g} / \mathrm{L}$; locoregional recurrence-free survival curves $(\mathrm{D})$ and disease specific survival curves $(\mathrm{E})$ of all patients with $\Delta \mathrm{Hb}$ level $\geq-15.00 \mathrm{~g} / \mathrm{L}$ and $\Delta \mathrm{Hb}$ level $<-15.00 \mathrm{~g} / \mathrm{L}$. Abbreviation: $\mathrm{RT}$, radiotherapy; $\mathrm{Hb}$, hemoglobin. 
Table 2 Univariate analysis with Kaplan-Meier method and log-rank test for LRFS, DMFS, DFS and DSS of 815 nasopharyngeal carcinoma patients.

\begin{tabular}{|c|c|c|c|c|c|c|c|c|c|}
\hline \multirow[t]{2}{*}{ Factors } & \multirow[t]{2}{*}{ No. of Patients } & \multicolumn{2}{|c|}{ LRFS } & \multicolumn{2}{|r|}{ DMFS } & \multicolumn{2}{|r|}{ DFS } & \multicolumn{2}{|c|}{ DSS } \\
\hline & & $\% \mathrm{a}$ & $P$ value & $\% \mathrm{a}$ & $P$ value & $\% a$ & $P$ value & $\%{ }^{a}$ & $P$ value \\
\hline Age (years) & & & 0.479 & & 0.179 & & 0.192 & & $<0.001$ \\
\hline$<44$ & 395 & 91 & & 88 & & 81 & & 88 & \\
\hline$\geq 44$ & 420 & 90 & & 85 & & 79 & & 76 & \\
\hline Gender & & & 0.184 & & 0.041 & & 0.024 & & 0.016 \\
\hline Male & 611 & 90 & & 85 & & 78 & & 79 & \\
\hline Female & 204 & 93 & & 90 & & 86 & & 88 & \\
\hline T stage ${ }^{b}$ & & & 0.120 & & 0.003 & & 0.001 & & $<0.001$ \\
\hline $\mathrm{T}_{1}$ & 87 & 96 & & 93 & & 91 & & 89 & \\
\hline $\mathrm{T}_{2}$ & 227 & 92 & & 93 & & 86 & & 88 & \\
\hline $\mathrm{T}_{3}$ & 298 & 90 & & 84 & & 76 & & 82 & \\
\hline $\mathrm{T}_{4}$ & 196 & 87 & & 80 & & 72 & & 68 & \\
\hline N stage ${ }^{b}$ & & & 0.023 & & $<0.001$ & & $<0.001$ & & $<0.001$ \\
\hline $\mathrm{N}_{0}$ & 115 & 94 & & 95 & & 90 & & 92 & \\
\hline $\mathrm{N}_{1}$ & 435 & 92 & & 90 & & 83 & & 85 & \\
\hline $\mathrm{N}_{2}$ & 333 & 88 & & 77 & & 71 & & 73 & \\
\hline $\mathrm{N}_{3 \mathrm{a}-\mathrm{b}}$ & 31 & 84 & & 74 & & 66 & & 64 & \\
\hline Treatment & & & 0.532 & & 0.003 & & 0.024 & & 0.019 \\
\hline CCRT & 449 & 92 & & 93 & & 86 & & 88 & \\
\hline NACT+RT & 366 & 90 & & 85 & & 79 & & 80 & \\
\hline Pre-RT Hb & & & 0.091 & & 0.254 & & 0.033 & & 0.144 \\
\hline$<130.00 \mathrm{~g} / \mathrm{L}$ & 268 & 87 & & 85 & & 76 & & 79 & \\
\hline$\geq 130.00 \mathrm{~g} / \mathrm{L}$ & 547 & 92 & & 87 & & 82 & & 83 & \\
\hline Post-RT Hb & & & 0.010 & & 0.684 & & 0.149 & & 0.008 \\
\hline$<130.00 \mathrm{~g} / \mathrm{L}$ & 545 & 84 & & 81 & & 79 & & 80 & \\
\hline$\geq 130.00 \mathrm{~g} / \mathrm{L}$ & 270 & 91 & & 85 & & 83 & & 85 & \\
\hline$\Delta \mathrm{Hb}$ & & & 0.024 & & 0.712 & & 0.185 & & 0.015 \\
\hline$\geq-15.00 \mathrm{~g} / \mathrm{L}$ & 447 & 89 & & 86 & & 83 & & 85 & \\
\hline$<-15.00 \mathrm{~g} / \mathrm{L}$ & 368 & 83 & & 85 & & 77 & & 78 & \\
\hline RT technique & & & 0.052 & & 0.851 & & 0.310 & & 0.262 \\
\hline IMRT/3D-CRT & 157 & 95 & & 85 & & 83 & & 85 & \\
\hline 2D-CRT & 658 & 89 & & 87 & & 79 & & 81 & \\
\hline
\end{tabular}

a Five-year survival rate, $\mathrm{b}$ according to the AJCC staging system 2010 clinical classification. Abbreviation: LRFS, locoregional recurrence-free survival; DMFS, distant metastasis-free survival; DFS, disease-free survival; DSS, disease specific survival; CCRT, concurrent chemoradiotherapy; NACT+RT, neoadjuvant chemotherapy followed by radiotherapy alone; RT, radiotherapy; Hb, hemoglobin; IMRT, intensity-modulated radiotherapy; 3D-CRT, three-dimensional conformal radiotherapy; 2D-CRT, two-dimensional conformal radiotherapy.

Table 3 Multivariate analysis with the Cox proportional hazards model for LRFS and DSS of the 815 nasopharyngeal carcinoma patients.

\begin{tabular}{|c|c|c|c|c|c|c|}
\hline \multirow[t]{2}{*}{ Factors } & \multicolumn{3}{|c|}{ LRFS } & \multicolumn{3}{|c|}{ DSS } \\
\hline & $P$ & HR & $95 \% \mathrm{CI}$ of $\mathrm{HR}$ & $P$ & HR & $95.0 \% \mathrm{CI}$ of $\mathrm{HR}$ \\
\hline Age ( $\geq 44$ yrs vs. $<44$ yrs $)$ & 0.445 & 1.213 & $0.739-1.991$ & $<0.001$ & 2.319 & $1.574-3.417$ \\
\hline Gender (female vs. male) & 0.119 & 0.590 & 0.304-1.146 & 0.011 & 0.525 & $0.319-0.864$ \\
\hline T stage $\mathrm{e}^{*}$ & 0.032 & 1.377 & $1.029-1.844$ & $<0.001$ & 1.510 & $1.211-1.881$ \\
\hline N stage $^{*}$ & 0.005 & 1.668 & $1.168-2.382$ & $<0.001$ & 1.862 & $1.456-2.381$ \\
\hline Treatment (CCRT vs. NACT+RT) & 0.442 & 0.749 & $0.358-1.566$ & 0.440 & 0.790 & $0.435-1.435$ \\
\hline Pre-RT Hb (<130.00 g/L vs. $\geq 130.00$ g/L) & 0.033 & 1.986 & $1.056-3.737$ & 0.117 & 1.429 & $0.915-2.231$ \\
\hline Post-RT Hb (<130.00 g/L vs. $\geq 130.00 \mathrm{~g} / \mathrm{L})$ & 0.011 & 1.896 & $1.158-3.106$ & 0.009 & 1.767 & $1.152-2.711$ \\
\hline$\Delta \mathrm{Hb}(<-15.00 \mathrm{~g} / \mathrm{L}$ vs. $\geq-15.00 \mathrm{~g} / \mathrm{L})$ & 0.026 & 1.586 & $1.058-2.377$ & 0.016 & 1.556 & $1.087-2.227$ \\
\hline
\end{tabular}

* According to the AJCC staging system 2010 clinical classification. Abbreviation: LRFS, locoregional recurrence-free survival; DSS, disease specific survival; yrs, years; $\mathrm{CCRT}$, concurrent chemoradiotherapy; $\mathrm{NACT}+\mathrm{RT}$, neoadjuvant chemotherapy followed by radiotherapy alone; $\mathrm{RT}$, radiotherapy; $\mathrm{Hb}$, hemoglobin; $\mathrm{HR}$, hazard ratio; $\mathrm{CI}$, confidence index.

\section{Discussion}

Chemoradiotherapy, especially concurrent chemoradiotherapy with or without adjuvant/neoadjuvant chemotherapy, established as the mainstay for treating LA-NPC by the National Comprehensive Cancer Network guidelines (www.nccn.org), has greatly increased the locoregional control and survival [17]. With myelosuppres- sive chemotherapy frequently combined with radiotherapy, anemia became prevalent, especially mild-to-moderate anemia which was usually neglected or avoided by oncologists and clinical trial reports [24]. Therefore, it is reasonable to evaluate the prognostic value of $\mathrm{Hb}$ decrease for NPC in the chemoradiotherapy setting. This study demonstrated that post- $\mathrm{RT} \mathrm{Hb}<130.00 \mathrm{~g} / \mathrm{L}$ and $\Delta \mathrm{Hb}<-15.00 \mathrm{~g} / \mathrm{L}$ are associated with poorer locoregional control and dis- 
ease-specific survival and CCRT is the most relevant factor predictive of post-RT $\mathrm{Hb}<130.00 \mathrm{~g} / \mathrm{L}$ and $\Delta \mathrm{Hb}<-15.00 \mathrm{~g} / \mathrm{L}$.

\section{Cut-off points for $\mathrm{Hb}$ levels}

In this study, ROC analysis was performed to define the critical cut-off points, where the Youden indexes were maximal. Since primary endpoint of the current research was DSS, the cut-off points of post-RT $<130.00 \mathrm{~g} / \mathrm{L}$ and $\Delta \mathrm{Hb}<-15.00 \mathrm{~g} / \mathrm{L}$, selected based on ROC analysis for DSS, were adopted to regroup patients. Previous studies reported prognostic role of different $\mathrm{Hb}$ levels for various tumors treated with radiotherapy or chemoradiotherapy, which were summarized in the supplementary table S2. However, they were not coincident with the timing of $\mathrm{Hb}$ measurement or the cut-off points for prognostication refinement. Our grouping criteria were partially consistent with some previous researches [5, 7, 10, 25]. The high and low level definitions were established based on the $\mathrm{Hb}$ levels where local control rate became stable $(>130 \mathrm{~g} / \mathrm{L}$ for female and $>145 \mathrm{~g} / \mathrm{L}$ for male) for HNSCC treated with definitive radiotherapy in the DAHANCA studies [26-27].

\section{CCRT contributes to more mild-to-moderate anemia}

Although neoadjuvant chemotherapy caused pre-RT $\mathrm{Hb}$ decrease, compared with the CCRT group without NACT (130.88 g/L vs. $143.39 \mathrm{~g} / \mathrm{L})$, radiotherapy alone did not obviously deteriorate post-RT $\mathrm{Hb}$ decrease $(128.36 \mathrm{~g} / \mathrm{L}$ vs. $130.88 \mathrm{~g} / \mathrm{L}$ with mean $\Delta \mathrm{Hb}$ of $-9.03 \mathrm{~g} / \mathrm{L})$. However, CCRT led to massive $\mathrm{Hb}$ decrease $(116.90 \mathrm{~g} / \mathrm{L}$ vs. $143.39 \mathrm{~g} / \mathrm{L}$ with mean $\Delta \mathrm{Hb}$ of $-19.78 \mathrm{~g} / \mathrm{L}$ ), which was in accord with the study for lung cancer by Koning CC et al [28]. More post-RT mild-to-moderate anemia was observed in the CCRT group, and CCRT proved to be the most relevant predictor for $\mathrm{Hb}$ decrease in multivariate analysis with binary logistic regression analysis. Explanations for the sharp $\mathrm{Hb}$ decrease might lie in the myelosuppressive toxicities of concurrent chemotherapy and worsening mucositis in the upper digestive tract, which contributed to nutritional insufficiency during CCRT.

\section{Hb decrease has a significant prognostic role in NPC treated with chemoradiotherapy}

Traditional and cogent explanations for how hypoxia in solid tumors induces radioresistance are based on several experimental radiobiological theories in an excellent review by Dewhirst MW et al [29]. The significance of $\mathrm{Hb}$ levels to treatment outcomes of NPC was previously investigated. Poorer locoregional control and survival were observed in the NPC sub- group receiving neoadjuvant chemotherapy followed by radiotherapy with pre- $\mathrm{RT} \mathrm{Hb}<110 \mathrm{~g} / \mathrm{L}$ and massive $\mathrm{Hb}$ decrease $\geq 15 \mathrm{~g} / \mathrm{L}$ after neoadjuvant chemotherapy in the research by Altum $\mathrm{M}$ et al [25]. Chua $\mathrm{DT}$ et al. found that mid-RT $\mathrm{Hb} \leq 110 \mathrm{~g} / \mathrm{L}$, the $25^{\text {th }}$ percentiles, was associated with impaired local control and DSS for the endemic NPC treated with radiotherapy with or without neoadjuvant chemotherapy [30]. However, only $\mathrm{Hb}$ decrease $>11.5 \mathrm{~g} / \mathrm{L}$ through treatment course predicted deteriorated locoregional control and DSS in early stage NPC treated with radiotherapy alone by Gao J et al [31]. The current study demonstrated that post- $\mathrm{RT} H \mathrm{Hb}<130.00 \mathrm{~g} / \mathrm{L}$ and $\Delta \mathrm{Hb}<-15.00 \mathrm{~g} / \mathrm{L}$ were significantly associated with poorer locoregional control and DSS both in the univariate and multivariate analysis for endemic NPC receiving chemoradiotherapy. However, the massive $\mathrm{Hb}$ decrease, compared with those in the studies by Altum $\mathrm{M}$ et al [25] and Gao J et al [31] respectively, indicated that chemoradiotherapy further contributed to anemia.

\section{The adverse prognostic value of $\mathrm{Hb}$ decrease suggests supportive care to prevent anemia}

Although combined treatment, especially concurrent chemoradiotherapy, greatly improved survivals for NPC, mild-to-moderate anemia became prevalent after CCRT and might to some extent count for the compromised LRFS and DSS in the subgroup with $\mathrm{Hb}$ decrease in this study, who did not received supportive care unless $\mathrm{Hb}<60 \mathrm{~g} / \mathrm{L}$. Treatment for mild-to-moderate anemia was generally avoided due to no alternative to blood transfusion or concern about the unfavorable effect of erythropoiesis-stimulating agents (ESA) on long-term survivals [32] or declined $\mathrm{Hb}$ level that triggered ESA treatment mandated by United States Food and Drug Administration [33]. However, comprehensive measures should be taken to prevent $\mathrm{Hb}$ decrease. Chemoradiotherapy toxicity, e.g., nausea and vomiting, anorexia, diarrhea, mucositis, which may result in nutritional imbalance and deficiency, should be reduced. And further studies are required to identify systemic approaches with less myelosuppression.

This is a single-institutional study with the largest sample size to report the prognostic role of chemoradiotherapy-induced $\mathrm{Hb}$ decrease in NPC patients. The principal limitation of the current study is its retrospective nature, which can be addressed by pooled analysis of several prospective multicenter clinical trials.

In conclusion, the incidence of mild-to-moderate anemia after chemoradiotherapy is high. Chemoradiotherapy-induced $\mathrm{Hb}$ decrease has negative influence on locoregional control and disease-specific survival, 
and may compromise the efficacy of neoadjuvant/concomitant chemotherapy plus radiotherapy. Further studies to investigate the impact of $\mathrm{Hb}$ level on treatment outcomes for NPC and the management of chemoradiotherapy-induced anemia are warranted.

\section{Supplementary Material}

Supplementary Table S1, Supplementary Table S2,

Supplementary Figure S1.

http://www.jcancer.org/v06p0502s1.pdf

\section{Acknowledgements}

Fang-Yun Xie conceived the study and revised the manuscript. Xue-Xia Liang interpreted and analyzed the data, and drafted the manuscript. Qun Li, Zhen Su, Xiao-Wen Lan, Pu-Yun Ouyang, Yan-Ping Mao, Ding-Bo Shi, Wu-Guo Deng, Zhi-Bin Cheng and Si-Yang Wang collected the data. All authors read and approved the final manuscript.

\section{Funding}

This work was supported by grants from the National Natural Science Foundation of China (81272195, 81071687, 81372133), the State "863 Program" of China (SS2012AA020403), the State "973 Program" of China (2014CB542005), the Sci-Tech Project Foundation of Guangdong Province (2006B36001009) and the State Key Laboratory of Oncology in South China.

\section{Competing Interests}

The authors have declared that no competing interest exists.

\section{References}

1. Gray LH, Conger AD, Ebert M, et al. The concentration of oxygen dissolved in tissues at the time of irradiation as a factor in radiotherapy. Br J Radiol. 1953; 26:638-48.

2. Semenza GL. Intratumoral hypoxia, radiation resistance, and HIF-1. Cancer Cell. 2004; 5:405-6.

3. Rades D, Stoehr M, Kazic N, et al. Locally advanced stage IV squamous cell carcinoma of the head and neck: impact of pre-radiotherapy hemoglobin level and interruptions during radiotherapy. Int J Radiat Oncol Biol Phys. 2008; 70:1108-14.

4. Serkies K, Badzio A, Jassem J. Clinical relevance of hemoglobin level in cervical cancer patients administered definitive radiotherapy. Acta Oncol. 2006; 45:695-701.

5. Rutkowski T, Suwinski R, Idasiak A. The prognostic value of hemoglobin concentration in postoperative radiotherapy of 835 patients with laryngeal cancer. Int J Radiat Oncol Biol Phys. 2007; 69:1018-23.

6. Macrae R, Shyr Y, Johnson D, et al. Declining hemoglobin during chemoradiotherapy for locally advanced non-small cell lung cancer is significant. Radiother Oncol. 2002; 64:37-40.

7. Roldan GB, Chan AK, Buckner M, et al. The prognostic value of hemoglobin in patients with anal cancer treated with chemoradiotherapy. Dis Colon Rectum. 2010; 53:1127-34.

8. Cefaro GA, Genovesi D, Vinciguerra A, et al. Prognostic impact of hemoglobin level and other factors in patients with high-grade gliomas treated with postoperative radiochemotherapy and sequential chemotherapy based on temozolomide: a 10-year experience at a single institution. Strahlenther Onkol. 2011; 187:778-83

9. Yurut-Caloglu V, Caloglu M, Kaplan M, et al. Pre-treatment hemoglobin levels are important for bladder carcinoma patients with extravesical extension undergoing definitive radiotherapy. Asian Pac J Cancer Prev. 2009; 10:1151-7.
10. Zenda S, Hironaka S, Boku N, et al. Impact of hemoglobin level on survival in definitive chemoradiotherapy for T4/M1 lymph node esophageal cancer. Dis Esophagus. 2008; 21:195-200.

11. Pehlivan B, Zouhair A, Luthi F, et al. Decrease in hemoglobin levels following surgery influences the outcome in head and neck cancer patients treated with accelerated postoperative radiotherapy. Ann Surg Oncol. 2009; 16:1331-6.

12. Abuzallouf S, Vasishta S, Ragheb A, et al. Prognostic value of hemoglobin levels prior to radiotherapy for cervical cancer--Kuwait experience. Gulf J Oncolog. 2008; 3:41-5.

13. Tarnawski R, Skladowski K, Maciejewski B. Prognostic value of hemoglobin concentration in radiotherapy for cancer of supraglottic larynx. Int J Radiat Oncol Biol Phys. 1997; 38:1007-11.

14. Becker A, Stadler P, Lavey RS, et al. Severe anemia is associated with poor tumor oxygenation in head and neck squamous cell carcinomas. Int J Radiat Oncol Biol Phys. 2000; 46:459-66.

15. Nordsmark M, Bentzen SM, Rudat V, et al. Prognostic value of tumor oxygenation in 397 head and neck tumors after primary radiation therapy: an international multi-center study. Radiother Oncol. 2005; 77:18-24.

16. Hamai Y, Hihara J, Taomoto J, et al. Hemoglobin level influences tumor response and survival after neoadjuvant chemoradiotherapy for esophageal squamous cell carcinoma. World J Surg. 2014; 38:2046-51.

17. Wei WI, Sham JS. Nasopharyngeal carcinoma. Lancet. 2005; 365:2041-54.

18. Kong L, Zhang YW, Hu CS, et al. Neoadjuvant chemotherapy followed by concurrent chemoradiation for locally advanced nasopharyngeal carcinoma. Chin J Cancer. 2010; 29:551-5.

19. Xie FY, Qi SN, Hu WH, et al. Comparison of efficacy of docetaxel combined cisplatin (TP regimen) and cisplatin combined 5-fluorouracil (PF regimen) on locally advanced nasopharyngeal carcinoma. Ai Zheng. 2007; 26:880-4. [In Chinese]

20. Xiao WW, Huang SM, Han F, et al. Local control, survival, and late toxicities of locally advanced nasopharyngeal carcinoma treated by simultaneous modulated accelerated radiotherapy combined with cisplatin concurrent chemotherapy: long-term results of a phase 2 study. Cancer. 2011; 117:1874-83.

21. Chen L, Hu CS, Chen XZ, et al. Concurrent chemoradiotherapy plus adjuvant chemotherapy versus concurrent chemoradiotherapy alone in patients with locoregionally advanced nasopharyngeal carcinoma: a phase 3 multicentre randomised controlled trial. Lancet Oncol. 2012; 13:163-71.

22. Chen Y, Liu MZ, Liang SB, et al. Preliminary results of a prospective randomized trial comparing concurrent chemoradiotherapy plus adjuvant chemotherapy with radiotherapy alone in patients with locoregionally advanced nasopharyngeal carcinoma in endemic regions of china. Int J Radiat Oncol Biol Phys. 2008; 71:1356-64.

23. Brizel DM, Dodge RK, Clough RW, et al. Oxygenation of head and neck cancer: changes during radiotherapy and impact on treatment outcome. Radiother Oncol. 1999; 53:113-7.

24. Groopman JE, Itri LM. Chemotherapy-induced anemia in adults: incidence and treatment. J Natl Cancer Inst. 1999; 91:1616-34.

25. Altun M, Demiral AN, Meral R, et al. Prognostic significance of hemoglobin concentration in nasopharyngeal carcinoma: does treatment-induced anemia have negative effect? In Vivo. 2003; 17:483-7.

26. Overgaard J, Hansen HS, Jorgensen $\mathrm{K}$, et al. Primary radiotherapy of larynx and pharynx carcinoma--an analysis of some factors influencing local control and survival. Int J Radiat Oncol Biol Phys. 1986; 12:515-21.

27. Hoff CM, Hansen HS, Overgaard M, et al. The importance of haemoglobin level and effect of transfusion in HNSCC patients treated with radiotherapy--results from the randomized DAHANCA 5 study. Radiother Oncol. 2011; 98:28-33.

28. Koning CC, Wouterse SJ, Daams JG, et al. Toxicity of concurrent radiochemotherapy for locally advanced non--small-cell lung cancer: a systematic review of the literature. Clin Lung Cancer. 2013; 14:481-7.

29. Dewhirst MW, Cao Y, Moeller B. Cycling hypoxia and free radicals regulate angiogenesis and radiotherapy response. Nat Rev Cancer. 2008; 8:425-37.

30. Chua DT, Sham JS, Choy DT. Prognostic impact of hemoglobin levels on treatment outcome in patients with nasopharyngeal carcinoma treated with sequential chemoradiotherapy or radiotherapy alone. Cancer. 2004; 101:307-16.

31. Gao J, Tao YL, Li G, et al. Involvement of difference in decrease of hemoglobin level in poor prognosis of Stage I and II nasopharyngeal carcinoma: implication in outcome of radiotherapy. Int J Radiat Oncol Biol Phys. 2012; 82:1471-78.

32. Bohlius J, Schmidlin K, Brillant C, et al. Recombinant human erythropoiesis-stimulating agents and mortality in patients with cancer: a meta-analysis of randomised trials. Lancet. 2009; 373:1532-42.

33. Stroupe KT, Tarlov E, Lee TA, et al. Hemoglobin levels triggering erythropoiesis-stimulating agent therapy in patients with cancer: the shift after United States Food and Drug Administration policy changes. Pharmacotherapy. 2012; 32:988-97. 